\title{
ESTETIKA TEKS DENDANG KAMPAR BASIANG: CERMINAN BUDAYA MASYARAKAT AGRARIS DI MINANGKABAU (ANALISIS TEKS)
}

\author{
Hendri Koto ${ }^{1 *}$, Andar Indra Sastra ${ }^{2 *}$ Asep Saepul Haris ${ }^{3 *}$ \\ Minat Penciptaan Seni Musik Nusantara Program Pascasarjana \\ Institut Seni Indonesia Padang Panjang \\ Jl. Bahder Johan, Guguak Malintang, Padangpanjang, Kota Padangpanjang, 27126. \\ Sumatera Barat. Indonesia. \\ Email: iethokoto@gmail.com
}

\begin{abstract}
Abstrak
Dendang kampar basiang adalah salah satu dendang yang terdapat pada kesenian saluang dendang di Minangkabau. Dendang tersebut dinilai memiliki aspek estetis pada teks yang membangun struktur pantunnya. Dilihat dari frase kalimat sampiran maupun isi, kecenderungan dalam teks pantun dendang kampar basiang memiliki kata maupun kalimat yang mengambarkan fenomena kehidupan masyarakat agraris. Penelitian ini bermaksud untuk menganalisis teks yang terdapat pada dendang kampar basiang yang dihubung-kaitkan dengan aspek sosial masyarakat Minangkabau pada umumnya. Dalam mengkaji fenomena tersebut, digunakan beberapa pendekatan telaah sastra dan estetika paradoks, serta dengan metode kualitatif. Terkait dengan hasil penalaahan teks dendang kampar basiang, maka didapati bahwa dendang tersebut merupakan sebuah cerminan dari kehidupan masyarakat agraris di Minangkabau.
\end{abstract}

Kata Kunci: estetika, agraris, dendang kampar basiang

\begin{abstract}
Kampar basiang dendang is a kind of songs in Minangkabau saluang dendang. This Dendang is considered to have aesthetic aspects of the text that build the rhyme structure. Seeing from the sentences phrase ofsampiran, as well as it's content, the tendency of dendang kampar basiangrhyme has a word or phrase that describes the phenomenon of agrarian society. This research intends to analyze the texts contained inkampar basiang dendang which is related to social aspect of Minangkabau society in general. Several approaches are used to examine this phenomenon, which is literary studies and paradox aesthetic, as well as qualitative methods.In relation to the study about the text of kampar basiang dendang, it has been found that dendang is a kind of reflection about the life of agrarian society in Minangkabau
\end{abstract}

Keywords: aesthetic, agrarian, kampar basiang dendang

\section{PENDAHULUAN}

Minangkabau dikenal memiliki berbagai macam bentuk sastra lisan yang sampai saat ini masih difungsikan sesuai dengan konteks adat maupun budaya lokal setempat. Diantaranya, seperti, pasambahan, kaba, petatah-petitih, pantun, dan banyak lagi yang lainnya. Dari berbagai bentuk sastra lisan Minangkabau, beberapa diantaranya dibawakan melalui berbagai macam penyajian. Seperti, kaba yang disajikan ke dalam bentuk kesenian seperti dalam rabab, kucapi, dan juga dibawakan dalam kesenian randai. Begitu juga dengan jenis pantun, yang juga sering dibawakan ke dalam bentuk kesenian saluang yang kemudian menjadi dendang.

Sastra lisan yang berbentuk dendang di Minangkabau sangat beragam pula jenisnya, seperti dendang pada saluang sampelong, saluang pauah, saluang panjang, dan saluang darek. Pada saluang darek, terdapat banyak pula jenis maupun klasifikasi dendang. Di dalam klasifikasi menurut konsep musikalnya, terdapat beberapa jenis dendang pada kesenian saluang darek seperti, dendang pakok sabalah, dendang pakok ciek, dendang pakok duo, dendang pakok tigo, dendang pakok panuah atau dendang pakok ampek.

Permasalahan yang menarik untuk dikaji di dalam fenomena kesenian saluang sangat banyak dan beragam. Hingga saat ini, dirasa masih minim pengamatan terhadap kesenian tersebut. Beberapa sudut pandang kajian dalam kesenian saluang seperti mengenai konsep musikal dari saluang, aspek musikologis dendang, dan analisis estetika teks 


\section{Gorga Jurnal Seni Rupa \\ Volume 07 Nomor 02 \\ p-ISSN: 2301-5942 | e-ISSN: 2580-2380}

dendang, terutama kaitannya dengan sosial masyarakat yang masih sangat jarang dilakukan oleh para peneliti. Untuk itu, dalam hal ini akan dibahas mengenai analisis estetika teks dari salah satu dendang, yaitunya dendang kampar basiang. Sebagai pertimbangan yang mendasar bahwa, teks yang menjadi syair merupakan aspek utama yang membangun struktur pantun pada setiap dendang.

Dendang kampar basiang merupakan salah satu dendang yang sering dibawakan pada pertunjukan saluang dendang. Dendang tersebut merupakan jenis dendang pakok tigo yang berasal dari wilayah Lima Puluh Kota. Seperti bentuk struktur dendang pada umumnya, dendang kampar basiang secara teks juga terdiri dari bait kalimat sampiran dan isi. Namun, yang berbeda dengan dendang pada umumnya, dendang kampar basiang terdiri dari tiga bait kalimat sampiran, dan tiga bait kalimat isi. Struktur seperti itu tidak banyak dimiliki oleh dendang-dendang pakok tigo ada umumnya.

Dilihat dari aspek teks pantun yang terdapat pada dendang kampar basiang, yang dalam hal ini mengacu pada hasil rekaman yang didendangkan oleh Melati sebagai salah satu tukang dendang di Minangkabau. Pada teks dendang kampar basiang yang didendangkan oleh Melati, banyak ditemui teks pantun yang secara verbal mencerminkan sisi keseharian masyarakat Minangkabau, seperti halnya kehidupan bertani. Hal tersebut merupakan suatu estetika tersendiri yang dihadirkan oleh pedendang dalam teks dendang yang dinyayikan, dan berkemungkinan berangkat dari pengalaman empirisnya.

Zainuddin Fananie berpandangan bahwa, estetika dalam karya sastra merupakan lingkaran yang tidak dipisahkankan. Penghargaan karya sastra tidak mungkin lepas dari nilai estetikanya (Zainuddin Fananie, 2001:74). Pendekatan ini bertolak dari pemikiran bahwa karya sastra merupakan refleksi kehidupan nyata. Refleksi ini terwujud berkat tiruan dan gabungan imajinasi pengarang terhadap realitas kehidupan atau realita alam (Zainuddin Fananie, 2001:111).

Sedangkan dalam melihat ciri sastra lisan tersebut, Hutomo berpandangan sastra lisan hidup subur di wilayah-wilayah yang tradisi tulisnya belum maju. Ciri lain diantaranya:

(a). Pada umumnya hidup dalam masyarakat tradisional; (b). Dianggap sebagai milik masyarakat bersama; (c). Oleh karena itu seolah-olah tidak ada pengarangnya, sehingga setiap orang bebas untuk menyalin, meresepsinya; (d). Oleh karena itu pula pada umumnya terdiri dari beberapa versi; (e). Tidak ada batas yang jelas antara fakta dan fiksi; (f). Sebagai karya sastra ciri lain yang juga penting adalah estetis, puitis, dan diucapkan secara berulang-ulang." (Hutomo, dalam Nyoman Kuta Ratna, 2011:107). Ciri mengenai sastra lisan yang dikemukan di atas juga menjadi ciri dari dendang-dendang yang ada di wilayah budaya Minangkabau, termasuk dendang kampar basiang. Sebagai bentuk kesenian yang dimiliki bersama, di dalam pelahirannya pun memiliki keragaman sesuai dengan estetika pedendang yang menyanyikan.

Untuk itu, dapat dirumuskan beberapa permasalahan yang akan menjadi bahasan pada bab selanjutnya. Diantara yang menjadi rumusan permasalahan pada bahasan ini adalah: (1). Bagaimana bentuk struktur teks dendang kampar basiang; (2). Bagaimana bentuk nilai estetika yang terkandung dalam teks dendang kampar basiang.

\section{KAJIAN TEORI}

Dalam melihat nilai dan estetika sebuah kebudayan yang hidup di tengah masyarakat, terutama kebudayan masyarakat di Nusantara. Tentunya harus dilihat melalui pendekatan filsafat estetika Timur agar terjadi kesesuaian dalam melihat nilai estetika yang terkandung pada kebudayaan. Sesuai dengan pandangan bangsa Timur pada umumnya, orang Indonesia mempunyai orientasi sikap keterkaitan kosmos dan peng-Esa-annya, sekaligus sikap berseni, sebagai berikut:

(1). Merasa terikat pada penguasa alam semesta sehingga timbul sikap taat, takut dan memujanya (keterkaitan vertikal); (2). Merasa terikat pada alam sekelilingnya dan tanah tempat ia berpijak, sehingga timbul sikap rasa syukur, yaitu: berterimakasih pada alam dan memuja penguasanya (keterkaitan vertikal); (3). Merasa terikat pada masyarakat lingkungannya, sesama manusia yang hidup di lingkungannya (keterikatan horizontal). (Dharsono Sony Kartika \& Nanang Ganda Perwira, 2004:187).

Pandangan tersebut merupakan sebuah bentuk nilai luhur yang tercermin dari masyarakat di Nusantara dalam aktivitas sosial dan kebudayaannya, yang juga tercermin di dalam teks dendang kampar basiang. Kosmologi masyarakat Nusantara juga identik dengan pola-pola yang terbentuk oleh falsafah hidup dalam memaknai kehidupan dan memelihara alam semesta, itu semua tercermin hampir pada setiap kebudayaan masyarakat di Nusantara. 


\section{Gorga Jurnal Seni Rupa \\ Volume 07 Nomor 02 \\ p-ISSN: 2301-5942 | e-ISSN: 2580-2380}

khas tersendiri pula dari segi penyajian dan isiannya. Ciri-ciri pantun Minangkabau menurut Boestanul Arifin Adam adalah: "Kalimat-kalimat sampiran dari sebuah pantun bersumber dari keadaan alam sekeliling, seperti kampung halaman; gunung-gunung; sawah-sawah; tepian tempat mandi; sungai-sungai; kehidupan para petani atau pedagang; nama atau gelar orang-orang yang baik hati serta suka menolong masalah di sekitar rumah tangga dan lain sebagainya (Boestanol Arifin Adam, 1980:41).

Dalam melihat serta menganalisis suatu permasalahan dalam penelitian biasanya dilakukan beberapa tahap melalui beberapa metode seperti, pengumpulan data, riset pustaka, analisis data, serta kesimpulan analisis data.

Pengumpulan data dilakukan dengan cara menghimpun data berupa teks, dan audio rekaman dendang kampar basiang. Riset pustaka dilakukan guna mendapatkan referensi berupa literatur-literatur yang membahas tentang analisis kajian dendang saluang sebagai rujukan model kajian, dan literatur konsep, serta teori yang akan dipakai untuk manganalisis data yang sudah dikumpulkan. Kemudian barulah masuk pada tahap analisis data guna mendapatkan simpulan terkait temuan dalam kajian.

\section{HASIL DAN PEMBAHASAN}

\section{Identifikasi Dendang dalam Aspek Sosial Masyarakat Minangkabau}

Terminologi dendang memiliki makna yang spesifik menurut pengunaan dan penyajiannya seperti yang dikemukan di atas. Dilihat dari etimologi kata, menurut Kamus Besar Bahasa Indonesia, dendang berarti 'nyanyian ungkapan rasa senang, gembira, dsb (sambil bekerja atau diiringi bunyibunyian)'(Departemen Pendidikan Dan Kebudayaan, 1999:11). Artinya secara khusus dendang merupakan jenis pantun yang dinyanyikan melalui penyajian yang diiringi oleh instrumen musik bersifat melodis dan dilakukan pada waktu senggang sebagai hiburan masyarakat.

Di dalam kehidupan masyarakat etnis Minangkabau, dendang merupakan salah satu bentuk representasi nilai kehidupan sosial budaya yang mencerminkan kehidupan masyarakatnya, dan dilahirkan ke dalam bentuk pantun-pantun. Pada umumnya masyarakat Nusantara mengenal pantun dan syair sebagai bagian dari sastra lisan, terutama masyarakat rumpun Melayu Sumatera. Setiap daerah memiliki bentuk pantunpantun dengan penyajian yang khas dalam konteks yang beragam. Di Minangkabau, pantun memiliki ciri
Beberapa bentuk tema pantun Minangkabau menurut pandangan Boestanul di atas, merupakan suatu cerminan ekspresi masyarakat agraris yang menceritakan pengalaman keseharian sebagai masyarakat penggarap lahan yang berprofesi sebagai petani. Beberapa tema yang dominan seperti kampung halaman, sawah-sawah, tepian tempat mandi, sungai, dan kehidupan sebagai petani adalah sebuah ciri khas masyarakat agraris sekaligus menjadi tema-tema yang dominan pada pantun di dalam dendang-dendang Minangkabau.

Masyarakat agraris dipandang sebagai masyarakat pedesaan yang mengandalkan hidup dari penguasaan lahan, serta berprofesi sebagai petani pengarap lahan. Koentjaraningrat mengemukakan definisi masyarakat sebagai kesatuan hidup manusia yang berinteraksi menurut suatu sistem adat-istiadat tertentu yang bersifat kontiniu, dan yang terikat oleh suatu idenitas bersama (Koentjaraningrat, 2000:146-147). Sedangkan istilah agraris berarti 'mengenai pertanian atau tanah pertanian, mengenai petani dan cara hidup petani'(Departemen Pendidikan Dan Kebudayaan, 1999:11)

Pada umumnya, masyarakat Minangkabau dikenal sebagai etnis yang gemar dalam melakukan aktivitas merantau sebagai usaha untuk meningkatkan kualitas ekonomi. Selain itu, bagi masyarakat yang hidup di kampung halaman juga memiliki usaha dan aktivitas ekonomi yang beragam seperti, menjadi pegawai, pedagang, petani, dan profesi lainnya. Diantara antara beberapa profesi yang digeluti masyarakat Minangkabau di kampung sebagian besar adalah petani. Hal tersebut disebabkan karena cukup luasnya lahan garapan terutama di wilayah Luhak Nan Tigo sebagai daerah sentral yang disebut juga wilayah luhak atau wilayah darek Minangkabau.

Kehidupan sosial masyarakat Minangkabau yang sebagian besar berprofesi sebagai petani penggarap lahan tersebut juga tercermin pada beberapa nomor lagu dendang dalam kesenian saluang darek. Beberapa diantaranya seperti, padang magek, solok 


\section{Gorga Jurnal Seni Rupa \\ Volume 07 Nomor 02 \\ p-ISSN: 2301-5942 | e-ISSN: 2580-2380}

bacangkeh, lintau barotan, lintau basiang, lawang mangilang tabu, randang kopi, singgalang parak kina, singgalang parak lobak, gaduik manuai, taram manuai, dan termasuk dendang kampar basiang yang akan menjadi pembahasan selanjutnya.

\section{Identifikasi Struktur Dendang Kampar Basiang}

Seni-seni yang dapat disaksikan pada saat ini, baik seni pertunjukan maupun seni rupa pada dasaranya adalah seni yang telah terbentuk secara mapan melalui proses panjang, dan semulanya merupakan sebuah bentuk seni yang sangat sederhana hingga menjadi seni kompleks. Sehingganya seni tersebut bisa hidup dan berkembang di tengah masyarakat pendukungnya, sekaligus diwarisi secara turun- temurun sebagai tradisi setempat yang diistilahkan sebagai kesenian.

Kesenian merupakan salah satu unsur dari kebudayaan. Kesenian timbul dan merupakan bagian terpenting dari pengalaman hidup manusia dalam mencari, menikmati dan mengagumi keindahan. Bentuk-bentuk keindahan yang beraneka-ragam itu timbul dari imajinasi yang kreatif dan memberikan kepuasan batin bagi manusia (Purwadi Suriadiredja, 2003:268). Pelahiran rasa estetis manusia yang dibalut dengan pengalaman empiris dan pengaruh lingkungan sekitar pada akhirnya menginspirasi manusia melahirkan sebuah karya seni dengan berbagai bentuk serta beragam.

Dendang merupakan salah satu jenis karya seni berbentuk pantun yang dinyanyikan dengan mengunakan instrument tradisi (saluang darek) sebagai pengiring. Seperti yang telah disebutkan sebelumnya bahwa, sebuah dendang berisikan pantunpantun dengan berbagai tema sesuai judul dendang dan kemahiran tukang dendang dalam melahirkan pantun yang diinginkan penikmat dalam konteks pertunjukan dendang itu sendiri. Biasanya setiap pantun yang ada pada sebuah dendang terdiri dari sampiran dan isi pantun. Boestanol mengemukakan bahwa, "sampiran" dan "isi" adalah pantun yang didendangkan. Biasanya sampiran dan isi lagu saluaeng masing-masing terdiri dari dua, tiga, empat sampai lima baris (Boestanol Arifin Adam, 1980:20). Secara umum, sampiran dan isi yang terdapat dalam dendang biasanya bersajak "a-b, a-b". Tanda "a" menunjukkan sampiran, sedangkan tanda "b" menunjukkan isi dari sebuah pantun.

Pada kasus pantun-pantun di Minangkabau, termasuk pantun yang terdapat dendang saluang, mempunyai ciri khas serta memiliki perbedaan jika dibandingkan dengan pantun-pantun Melayu pada umumnya. Isi pantun-pantun di Minangkabau tidak dijelaskan secara langsung, tidak disampaikan secara terus-terang, tetapi melalui kiasan-kiasan dan sindiran-sindiran, yang diangkat dari alam sekitar (Boestanol Arifin Adam, 1980:39). Kecenderungan tersebut juga terdapat pada salah satu dendang kampar basiang. Berikut ini adalah teks dendang kampar basiang:

\section{Kampar Basiang}

a. Nan disiang padi disiang

Gabak di hulu lah ka hujan

Kok untuang hujan lai jatuah

Oi saluang tolong himbaukan

b. Buah labek tangkai lah panjang

Jo tangih batang maanjuangkan

Jan lupo bumi tampek tumbuah

Oi saluang tolong himbaukan

a. Sawah ditimpo hujan sanjo

Rabahlah padi ka pamatang

Dilendo aia dari hulu

Oi saluang tolong himbaukan

b. Nan kok pipik dapek digarok

Nan barek musuah jo pianggang

Lah ampo sajo awak tau

Oi saluang tolong himbaukan

a. Lah paneh hari lah paneh

Nan lah kamih candonyo buruang

Usah talengah rang panggarok

Oi saluang tolong himbaukan

b. Kok lai sampai babuah boneh

Nan sabatang ka masuak lumbuang

Rumpun di sawah kana juo

Oi saluang tolong himbaukan

a. Kok sampai lamo hari paneh

Baanyo padi ka disiang

Rumpuik batambah panjang juo

Oi saluang tolong himbaukan

b. Mamintak ampo ka nan boneh

Asa kami tabawo pulang

Sahinggo janjang jadi juo

Oi saluang tolong himbaukan

a. Nan lah kalam gunuang sabalik

Tandonyo hari lah ka hujan

Basiang padi malah kito

Oi saluang tolong himbaukan 


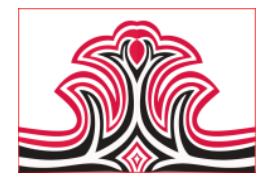

b. Padi nan masak ka basabik

Salibu usah ditinggakan

Tagalu-galu dapek juo

Oi saluang tolong himbaukan

Apabila dilihat dari teks dendang kampar basiang di atas, maka dapat disimpulkan bentuk sampiran dan isi yang membentuk struktur pantun dari dendang tersebut. Terdapat sepuluh bait pantun, yang masingmasing bait merupakan kalimat sampiran dan isi pantun yang terdiri dari tiga baris seperti, kalimat dalam sampiran: "nan disiang padi disiang", "gabak di hulu lah ka hujan”, "kok untuang hujan lai jatuah”. Kalimat isi: "buah labek tangkai lah panjang”, "jo tangih batang maanjuangkan”, "jan lupo bumi tampek tumbuah". Sedangkan teks "oi saluang tolong himbaukan", bisa dikatakan sebagai pelengkap atau ornamen kalimat yang mempertegas kalimat sampiran maupun isi, dikarekan kalimat tersebut hadir sesudah tiga kalimat awal sampiran dan kalimat isi.

Tabel 1. Struktur Dendang Kampar Basiang

\begin{tabular}{|c|c|c|c|}
\hline Struktur dendang & Bait kalimat & Bentuk teks kalimat & Ket. \\
\hline Sampiran & $\begin{array}{l}\text { Nan disiang padi disiang } \\
\text { Gabak di hulu lah ka } \\
\text { hujan } \\
\text { Kok untuang hujan lai } \\
\text { jatuah }\end{array}$ & Fenomena alam & \\
\hline $\begin{array}{l}\text { Ornamen kalimat } \\
\text { sampiran }\end{array}$ & $\begin{array}{l}\text { Oi saluang tolong } \\
\text { himbaukan }\end{array}$ & $\begin{array}{c}\text { Kalimat penegasan } \\
\text { untuk } \\
\text { mengkomunikasi } \\
\text { kalimat sampiran }\end{array}$ & \\
\hline Isi & $\begin{array}{c}\text { Buah labek tangkai lah } \\
\text { panjang } \\
\text { Jo tangih batang } \\
\text { maanjuangkan } \\
\text { Jan lupo bumi tampek } \\
\text { tumbuah }\end{array}$ & $\begin{array}{c}\text { Kiasan dan sindiran } \\
\text { yang mengandung } \\
\text { makna }\end{array}$ & \\
\hline $\begin{array}{c}\text { Ornamen kalimat } \\
\text { isi }\end{array}$ & $\begin{array}{l}\text { Oi saluang tolong } \\
\text { himbaukan }\end{array}$ & $\begin{array}{c}\text { Kalimat penegasan } \\
\text { untuk } \\
\text { mengkomunikasi } \\
\text { kalimat isi }\end{array}$ & \\
\hline
\end{tabular}

Seperti yang dikatakan Boestanol sebelumnya bahwa, ciri dari sebuah kalimat sampiran pantun biasanya berhubungan dengan alam sekitar. Sedangkan kalimat isi berbentuk kiasan-kiasan dan sindiran. Maka dapat dikelompokkan kalimat sampiran dan isi pada teks dendang kampar basiang. Kalimat sampiran sebagai berikut:

a. Nan disiang padi disiang

Gabak di hulu lah ka hujan

Kok untuang hujan lai jatuah

Oi saluang tolong himbaukan

a. Sawah ditimpo hujan sanjo

Rabahlah padi ka pamatang

Dilendo aia dari hulu

Oi saluang tolong himbaukan

a. Lah paneh hari lah paneh

\author{
Gorga Jurnal Seni Rupa \\ Volume 07 Nomor 02 \\ p-ISSN: 2301-5942 | e-ISSN: 2580-2380
}

Nan lah kamih candonyo buruang

Usah talengah rang panggarok

Oi saluang tolong himbaukan

a. Kok sampai lamo hari paneh

Baanyo padi ka disiang

Rumpuik batambah panjang juo

Oi saluang tolong himbaukan

a. Nan lah kalam gunuang sabalik

Tandonyo hari lah ka hujan

Basiang padi malah kito

Oi saluang tolong himbaukan

Sedangkan kalimat isi sebagai berikut:

b. Buah labek tangkai lah panjang

Jo tangih batang maanjuangkan

Jan lupo bumi tampek tumbuah

Oi saluang tolong himbaukan

b. Nan kok pipik dapek digarok

Nan barek musuah jo pianggang

Lah ampo sajo awak tau

Oi saluang tolong himbaukan

b. Kok lai sampai babuah boneh

Nan sabatang ka masuak lumbuang

Rumpun di sawah kana juo

Oi saluang tolong himbaukan

b. Mamintak ampo ka nan boneh

Asa kami tabawo pulang

Sahinggo janjang jadi juo

Oi saluang tolong himbaukan

b. Padi nan masak ka basabik

Salibu usah ditinggakan

Tagalu-galu dapek juo

Oi saluang tolong himbaukan

Pengelompokkan kalimat per-kalimat pantun seperti di atas merupakan suatu kaidah yang umum dalam melihat sebuah bentuk sastra lisan, khususnya pantun. Maka dapat disimpulan sementara bahwa pada dendang kampar basiang memiliki sepuluh bait pantun, lima diantaranya bait sampiran, dan lima bait isi. Terdapat empat puluh frase kalimat yang terdiri dari lima belas frase kalimat sampiran, lima belas frase kalimat isi, dan sepuluh frase kalimat pelengkap atau ornamen.

3.Analisis Nilai Estetika pada Dendang Kampar Basiang 


\section{Gorga Jurnal Seni Rupa \\ Volume 07 Nomor 02 \\ p-ISSN: 2301-5942 | e-ISSN: 2580-2380}

Dendang kampar basiang merupakan jenis dendang yang berasal dari wilayah luhak Lima Puluh Kota (Wawancara dengan M. Halim Pada Tanggal 13 Mei 2015). Dendang pada kesenian saluang di Minangkabau diklasifikasikan menurut wilyah geografisnya. Boestanol yang menyatakan bahwa, dilihat dari aspek geografis dan kecenderungan tangga nada yang digunakan, ada empat klasifikasi dendang seperti: empat nada di Singgalang; lima nada di Luhak Agam dan Luhak Tanah Data; enam dan tujuh nada di Luhak Limopuluah (Boestanol Arifin Adam: 1980:1619). Namun, pada umumnya dendang di Minangkabau terdiri dari beberapa jenis apabila dikaitkan dengan aspek wilayah geografisnya seperti, Singgalang, Tanah Datar, Agam, Lima Puluh Kota, Solok, Pariaman, dan lainnya.

Apabila dilihat dari judul dendang kampar basiang, bisa diyakini bahwa dendang tersebut berasal dari wilayah Lima Puluh Kota. Pemakaian kata "kampar" merupakan penegasan nama wilayah tempat dendang tersebut berasal. Kampar dulunya sebelum masuk wilayah administratif Provinsi Riau, merupakan daerah yang berada dalam kabupaten Lima Puluh Kota ketika masih dalam status wilayah Sumatera Tengah. Bahkan, jauh sebelum ditetapkannya bentuk daerah menjadi provinsi-provisi di Indonesia, daerah Kampar masuk dalam wilayah budaya Minangkabau. Hal senada juga disampaikan oleh Gerard Moussay dalam bukunya Tata Bahasa Minangkabau, tentang daerah yang masuk ke dalam wilayah Minangkabau, yang menyebutkan bahwa: "Secara tradisional, ranah Minangkabau dahulunya membentang hingga Sungai Kampar di sebelah Timur, dan masuk jauh ke pedalaman, di sepanjang Sungai Indragiri dan Sungai Batang Hari, di sebelah tenggara. Di sebelah selatan, negeri itu membentang hingga Kerinci dan Bengkulu.

Kini, dapat dianggap bahwa bahasa Minangkabau digunakan sampai Padang Sidempuan, tempat bermulanya wilayah bahasa Batak ke arah utara. Di sebelah timur sampai Bangkinang dan Kuantan, yang berbatasan dengan wilayah bahasa Melayu Riau. Gunung Kerinci dan bahasa Rejang Lebong” (Moussay Gerard, 1998:9).

Pemetaan wilayah Minangkabau secara tradisional menurut data yang dikemukakan Moussay merupakan sebuah bentuk upaya pemetaan bahasa serta dialek di berbagai daerah serta nagari di Minangkabau yang sangat beragam. Untuk itu, mengacu pada bahasan daerah yang mengacu pada data tersebut. Maka dapat disimpulkan sementara bahwa Kampar adalah wilayah Timur Minangkabau.
Masyarakat yang berada di wilayah budaya Minangkabau, dikenal hingga saat ini dengan pandangan hidup adat basandi syarak, syarak basandi kitabullah. Merupakan sebuah penyatuan dua konsep, antara adat dan agama yang bersinerji hingga menghasilakan suatu falsafah yang dipegang teguh oleh masyarakat Minangkabau sebagai pengaruh besar ajaran agama Islam. Namun jauh sebelumnya, masyarakat etnis Minangkabau telah melalui beberapa tahapan peradaban dan pengaruh beberapa ajaran, dimulai dari masa Animisme, Hindu-Budha, dan Islam. Sama halnya dengan masyarakat Nusantara pada umumnya, masyarakat Minangkabau juga berada dalam masa Animisme selama berabad-abad sekitar periode sebelum masehi. Lebih kurang dua belas abad dipengaruhi oleh ajaran dan peradaban Hindu-Budha, dan pengaruh ajaran Islam yang intens selama lima abad hingga saat ini.

Pengaruh-pengaruh peradaban yang telah dilalui masyarakat di Nusantara pada akhirnya membentuk tatanan nilai dan pola budaya yang sangat beragam, serta sinkretis. Selain itu, letak geografis juga menjadi faktor yang mempengaruhi pembentukan budaya masyarakatnya. Kawasan Nusantara terdiri dari pulaupulau besar dan kecil yang dikelilingi kawasan perairan, ada masyarakat pesisir dan masyarakat pegunungan. Maka dari itu, Jakob Sumardjo dalam Estetika Paradoks, membagi beberapa klasifikasi masyarakat primordial Nusantara dengan melihat kecenderungan pola-pola yang digunakan dalam kebudayaannya. Ada beberapa pola yang dibahas terkait masalah estetika yakninya "pola dua" sebagai masyarakat peramu; "pola tiga" sebagai masyarakat peladang; "pola empat" sebagai masyarakat pesisir; "pola lima" sebagai kecenderungan masyarakat pesawah (Jakob Sumardjo, 2006:33-182).

Masyarakat pemilik budaya dendang di Minangkabau merupakan ciri masyarakat "peladang". Karena dendang adalah pantun yang dinyanyikan dalam sebuah pertunjukan. Pantun yang berbentuk dendang merupakan salah satu jenis sastra tutur yang disebut badendang di Minangkabau, selain itu juga ada bakaba dan bapasambahan. Jakob Sumardjo kembali mengemukakan kembali dalam sumber yang sama bahwa, seni bertutur merupakan produk budaya masyarakat peladang. Seni bertutur hampir terdapat di daerah-daerah suku yang berbukit-bukit, jadi hidup dari berladang (Jakob Sumardjo, 2006:134).

Seni bertutur sudah amat tua usianya di Indonesia, karena menduduki fungsi religi suku. Namun dalam 


\section{Gorga Jurnal Seni Rupa \\ Volume 07 Nomor 02 \\ p-ISSN: 2301-5942 | e-ISSN: 2580-2380}

perkembangannya, beberapa seni bertutur berubah fungsi semata-mata untuk kepentingan profan, bukan sebagai ritual reliji (Jakob Sumardjo, 2006:135). Hal senada juga dikemukakan oleh beberapa etnomusikolog, yang berpandangan bahwa musik vokal (istilah etnomusikologi) adalah seni tutur seperti halnya dendang yang disajikan dengan iringan instrumen musik, merupakan budaya asli masyarakat tempat musik itu hidup, jika dibandingkan instrumen musiknya. Bose mengungkapkan, gaya instrumental sangat berbeda dari gaya vokal karena instrumen musik bukanlah asli dari kebudayaan yang bersangkutan (Bose, dalam Bruno Netll, 2012:204). Artinya bahwa, musik vokal seperti halnya dendang dan seni tutur atau sastra lisan lainnya diyakini merupakan kebudayaan asli masyarakat Minangkabau.

Jika dilihat beberapa kata yang membangun struktur pantun dendang kampar basiang, banyak mengunakan kata-kata yang berhubungan dengan alam sekitar terutama pada kalimat-kalimat sampiran, seperti gunuang, hulu, bumi, aia, hujan, paneh, padi, buruang, pianggang, sawah, pamatang. Apabila katakata tersebut dibagi sesuai klasifikasi estetika masyarakat primordial seperti dalam pandangan Jakob Sumardjo, maka kecenderungannya mencerminkan estetika pola tiga masyarakat peladang. Menurut Jakob Sumardjo mengenai ciri masyarakat pola tiga adalah:

"Masyarakat ini (pola tiga) hidup dari usahanya sendiri, yakninya berladang. Petani ladang hidup dari menciptakan (menanam), memelihara, dan mengembangkan padi, serta tanam-tanaman sampingan lainnya. Obesesinya adalah "menghidupkan". Mereka harus merawat dan memelihara tanaman pokoknya agar terus hidup. Pikiran mereka jauh dari "merampas" yang hidup. Bukan mematikan. Hidup adalah memelihara kehidupan. Bagaimana kehidupan agar tetap terus dipelihara? Dari mengawinkan pasangan kembar oposisi yang saling bertentangan, tetapi saling melengkapi. Dari perkawinan kehidupan baru muncul. Begitu terjadi pada manusia, pada hewan, pada tumbuhan, pada alam. Tanaman padi dapat terus hidup kalau ada "perkawinan" antara langit dan bumi. Langit mencurahkan hujan kepada tanah yang kering. Dengan demikian langit itu "basah" dan bumi

"kering". Basah itu asas perempuan dan kering asas lelaki” (Jakob Sumardjo, 2006:72).

Konsep "memelihara" bagi masyarakat pola tiga tercermin pada aktivitas "manyiang", "disiang", "basiang", (yang juga menjadi bagian kata judul dendang kampar basiang). Basiang, berarti aktivitas memelihara dalam bentuk membersihkan lahan yang telah ditumbuhi tanaman (termasuk padi) dari hama hewan dan tumbuhan agar kelak mendapatkan hasil panen yang memuaskan. Sedangkan konsep "menghidupkan" melalui proses "mengawinkan" merupakan suatu proses alami yang memanfaatkan tanah di bumi, dengan hujan dan matahari dari langit untuk menghidupi tanaman padi dan lainnya. Perkawinan keduanya akan menciptakan entitas ketiga, yakninya kehidupan di muka bumi. Langit di atas, Bumi di bawah, dan kehidupan muncul di tengah-tengah langit dan bumi (Jakob Sumardjo, 2006:72).

Pembagiannya antara lain "dunia atas" yang disimbolkan oleh hujan, paneh (matahari, langit); "dunia bawah" disimbolkan oleh sawah, pamatang (tanah, bumi); sedangkan "dunia tengah" adalah kehidupan yang ada di antara dunia atas dan dunia bawah yakninya, padi, buruang, dan pianggang (mahkluk hidup) sebagai sebuah bentuk kehidupan di atas muka bumi yang dihasilkan oleh keselarasan antara langit dan bumi sebagai alam semesta ciptaan yang kuasa.

Tabel 2. Konsep Pola Tiga pada Dendang Kampar Basiang

\begin{tabular}{|c|c|c|c|}
\hline Konsepsi pola tiga & Simbol & $\begin{array}{c}\text { Komponen- } \\
\text { komponen }\end{array}$ & Ket. \\
\hline Dunia atas & Langit & $\begin{array}{c}\text { Gabak, hulu, hujan, } \\
\text { paneh, kalam, } \\
\text { gunuang. }\end{array}$ & \\
\hline Dunia tengah & Kehidupan & $\begin{array}{c}\text { Padi, pipik, } \\
\text { pianggang, burvang, } \\
\text { rang panggarok, } \\
\text { lumbuang, rumpun, } \\
\text { rumpuik, ampo, } \\
\end{array}$ & \\
& & $\begin{array}{c}\text { boneh, salibu, tagalu- } \\
\text { galu. }\end{array}$ & \\
\hline Dunia bawah & Bumi & $\begin{array}{c}\text { Bumi, sawah, } \\
\text { pamatang, janjang. }\end{array}$ & \\
\hline
\end{tabular}

Berkaitan dengan tumbuh-tumbuhan seperti yang disebutkan di atas yaitunya, padi sebagai simbol kehidupan yang dihasilkan oleh konsepsi dunia atas dan dunia bawah. Masyarakat Minangkabau juga merupakan masyarakat yang mengantungkan hidupnya dari hasil berladang yang salah satunya adalah menanam padi. Maka dari itu, padi merupakan salah satu tumbuhan yang memiliki peran penting untuk kebutuhan sehari-hari sekaligus sebagai bagian dari pengerak sistem ekonomi masyarakat di pedesaan umumnya. Hal tersebut telah berlangsung beberapa lama semenjak masyarakat telah mengenal cara hidup bercocok tanam yang merupakan transisi dari periode masyarakat peramu yang mengantungkan hidupnya dengan berburu dan hidup berpindah-pindah. Maka dari itu, di Minangkabau banyak terdapat upacara yang dilakukan untuk menghormati padi yang biasanya dilakukan setelah panen. 


\section{Gorga Jurnal Seni Rupa \\ Volume 07 Nomor 02 \\ p-ISSN: 2301-5942 | e-ISSN: 2580-2380}

Menurut kepercayaan orang Minangkabau dulu, yakni sebelum agama Islam menyebar masuk ke daerah ini, konon kabarnya setiap petak sawah dilindungi oleh Dewi yang bernama Saniang Sari atau yang disebut juga Silan Sari, Sang Hyang Sri atau pun Dewi Sri (Anas Nafis, 2004:25). "Hyang" adalah istilah untuk menyebutkan dewa dalam kepercayaan masyarakat Nusantara sebelum masuknya ajaran Hindu-Budha. Sedangkan "Sri" diduga kuat ada hubungannya dengan masuknya pengaruh ajaran Hindu-Budha ke Nusantara. Hampir seluruh daerah di Nusantara mempercayai Sri atau Dewi Sri sebagai dawi/dewa padi yang memberikan kesuburan bagi lahan dan tanaman dalam budaya bertani. "Hyang Sri" di dalam Kamus Sansekerta - Indonesia berarti 'dewi sri, dewi padi, dewi kesuburan'(Purwadi \& Eko Priyo Purnomo, 2005:52).

Sama halnya dengan masyarakat di Minangkabau yang mempercayai adanya kekuatan tertentu yang memberi kesuburan serta memberi hasil panen yang melimpah. Masyarakat Minangkabau percaya bahwa, melindungi padi cukup dengan pertolongan Dewi Sri, asal saja yang punya sawah berpandai-pandai dengan sang dewi (Anas Nafis, 2004:25). Hal tersebut juga diperlengkap oleh pernyataan dari buku berjudul Animisme di Minangkabau, yang merupakan kumpulan cerita yang disadur dari beberapa sumber, salah satunya tentang tulisan yang berjudul "Dewi sang Pelindung" yang disadur dari "Berita Koto Gadang Th. IX - 1934”, yang menyatakan bahwa:

"Perhatian atau kepercayaan mereka terhadap padi sangat istimewa sekali. Mereka sangat menghormati "induak padi" (induk padi), yaitu padi yang terdiri dari beberapa tangkai dan buahnya sebagai wakil dari "Saniang Sari" (Sang Hyang Sri, Dewi Sri atau Silansari) yang dikeramatkan sebagai pelindung padi yang dihormati dan diupacarakan ketika waktu menanam, memanen serta menyimpan padi ke dalam sebuah lumbung atau rangkiang" (Anas Nafis, 2004:xii).

Sampai sekarang pun kepercayaan mengenai Dewi Sri ini belum hilang benar, bahkan di beberapa tempat atau desa (nagari) masih dipercayai orang. Kepercayaan tersebut dalam masyrakat Minangkabau agaknya termanifestasikan ke dalam kegiatan-kagiatan upacara sebelum menanam hingga memanen padi dengan berbagai bentuk kegiatan, untuk menghormati kekuatan-kekuatan yang kasat mata. Sikap kepercayaan tersebut diwujudkan dalam berbagai macam aktivitas seperti, ritual-ritual, maupun dalam bentuk kesenian. Ada juga dalam bentuk cara yang sederhana, dengan membacakan matra-matra tertentu. Salah satu mantra yang diperuntukkan oleh roh padi dalam kepercayaan masyarakat peladang di Minangkabau, seperti yang dikutip dalam buku Animisme di Minangkabau:

Mantra:

"Saniang Sari janganlah terkejut kerena orang melintas, jangan terkejut karena guruh dan petir. Kalau hujan pencuci muka, kalau panas bawalah gelak, setangkai jadikan sesukat, serumpun jadikan seketiding" (Anas Nafis, 2004:27).

Konsep memelihara dan menghidupkan adalah falsafah hidup yang dipegang teguh oleh masyarakat peladang, yang sekaligus menjadi konsep kosmologinya. Selain dua konsep tersebut, juga terdapat konsep "hulu" yang juga dianggap sebagai "asal". Hulu bagi manusia primordial Indonesia adalah tempat asal kehidupan, akar dari kehidupan ini. Tidak ada hulu, tidak ada hidup (Jakob Sumardjo, 2006:37). Seperti yang terdapat pada penggalan kalimat pantun dendang kampar basiang yakninya, gabak di "hulu" lah $\mathrm{ka}$ hujan. Kalimat tersebut menandakan suatu makna bahwa:

"Manusia peladang hanya mengenal dua orientasi arah kosmik, yakni hulu dan hilir, gunung dan laut, kemudian baru ada kiri dan kanan sungai, menghadapi dan membelakangi sungai, hulu itu arah asal (sangkan) dan hili arah tujuan (parani). Yang asal itu bersih, murni, penuh daya-daya, sakral. Sedang hilir jauh di depan yang sakral (profan). Inilah orientasi arah yang transenden, surgawi. Arah yang menyilangi, kanan dan kiri, depan dan belakang, merupakan arah yang imanen. Yang transenden, dan yang imanen bertemu tengah-tengah ruang. Dunia tengah kaum peladang" (Jakob Sumardjo, 2006:83).

Konsep hulu bagi masyarakat peladang merupakan suatu daya yang dipercayai mampu memberikan enerji yang kuat bagi kehidupan bagi makhluk hidup. Seperti halnya hulu sungai yang mengaliri air sebagai sumber kehidupan makhluk hidup yang berada di aliran sungai tersebut. Hulu biasanya merupakan penunjuk bagi wilayah ketinggian, yang juga erat kaitannya dengan konsep gunung bagi masyarakat peladang. Masyarakat peladang mengenal konsep gunung yang hampir sama dengan konsep hulu. Seperti pada salah satu penggalan bait kalimat pada pantun dendang kampar basiang yaitunya: nan lah kalam "gunuang” sabalik, tandonyo hari lah ka hujan, basiang padi malah kito. 
Setelah dilihat dari pemakaian kata dalam teks pantun dendang kampar basiang, terdapat kesesuain dengan konsep estetika pola tiga dari masyarakat peladang menurut Jakob Sumardjo. Namun, untuk lebih memperlengkap analisis tentang estetika dari dendang kampar basiang, maka juga perlu dilihat aspek makna yang terkandung dalam pantunnya. Pengungkapan makna teks pantun juga sebagai upaya penafsiran sebuah teks budaya seperti yang dikemukakan Ahimsa melalui pendekatan hermeneutik, dalam artian menerangkan atau menafsirkan. Ahimsa menyatakan bahwa, "menerangkan" dalam kajian tekstual berarti "mengungkapkan makna" dari sebuah teks, karenanya apa yang diuraikan bukanlah pemaparan sebab-akibat, tetapi pengertian-pengertian yang ada di balik apa yang tersurat, pengertian di balik teks (Ahimsa-Putra (ed), 2000:403). Maka dari itu, untuk digunakan pendekatan teori referensial yang melihat hubungan antara, kata-kata, kalaimat-kalimat, dan dunia pengalaman yang nonlingusitik.

Tabel 3. Kalimat Sampiran Dendang Kampar Basiang

\begin{tabular}{|c|c|c|c|}
\hline Sampiran & Kata & Kalimat & Makna \\
\hline Sampiran bait 1 & $\begin{array}{l}\text { Padi, gabak, hulu, } \\
\text { hujan. }\end{array}$ & $\begin{array}{c}\text { Nan disiang padi } \\
\text { disiang } \\
\text { Gabak di hulu lah ka } \\
\text { hujan } \\
\text { Kok untuang hujan } \\
\text { lai jatuah }\end{array}$ & \\
\hline Sampiran bait 2 & $\begin{array}{c}\text { Sawah, hujan, sanjo, } \\
\text { padi, pamatang, aia, } \\
\text { hulu. }\end{array}$ & $\begin{array}{l}\text { Sawain ditimpo hujan } \\
\text { sanjo } \\
\text { Rabahlah padi ka } \\
\text { pamatang } \\
\text { Dilendo aia dari hulu }\end{array}$ & \\
\hline Sampiran bait 3 & $\begin{array}{l}\text { Paneh, buruang, } \\
\text { panggarok. }\end{array}$ & $\begin{array}{l}\text { Lah paneh hari lah } \\
\text { paneh } \\
\text { Nan lah kamih } \\
\text { candonyo buruang } \\
\text { Usah talengah rang } \\
\text { panggarok }\end{array}$ & \\
\hline Sampiran bait 4 & Paneh, padi, rumpuik. & $\begin{array}{l}\text { Kok sampai lamo } \\
\text { hari paneh } \\
\text { Baanyo padi ka } \\
\text { disiang } \\
\text { Rumpuik batambah } \\
\text { panjang juo }\end{array}$ & \\
\hline Sampiran bait 5 & $\begin{array}{l}\text { Kalam, gunuang, } \\
\text { hari, hujan, padi. }\end{array}$ & $\begin{array}{c}\text { Nan lah kalam } \\
\text { gunuang sabalik } \\
\text { Tandonyo hari lah ka } \\
\text { hujan } \\
\text { Basiang padi malah } \\
\text { kito }\end{array}$ & \\
\hline
\end{tabular}

Tabel 4. Kalimat Sampiran Dendang Kampar Basiang

\begin{tabular}{|c|c|c|c|}
\hline Isi & Kata & Kalimat & Makna \\
\hline Isi bait 1 & $\begin{array}{l}\text { Buah, tangkai, } \\
\text { batang, bumi. }\end{array}$ & $\begin{array}{l}\text { Buah labek tangkai } \\
\text { lah panjang } \\
\text { Jo tangih batang } \\
\text { maanyuangkan } \\
\text { Jan lupo bumi } \\
\text { tampek tumbuah }\end{array}$ & $\begin{array}{c}\text { Pesan untuk } \\
\text { mengingatkan arti } \\
\text { penting sebuah } \\
\text { perjuangan }\end{array}$ \\
\hline Isi bait 2 & $\begin{array}{c}\text { Pipik, pianggang, } \\
\text { ampo. }\end{array}$ & $\begin{array}{l}\text { Nan kok pipik dapek } \\
\text { digarok } \\
\text { Nan barek musuah jo } \\
\text { pianggang } \\
\text { Lah ampo sajo cwak } \\
\text { tau }\end{array}$ & $\begin{array}{l}\text { Kewaspadaan atas } \\
\text { sekecil apapun } \\
\text { bahaya yang akan } \\
\text { datang }\end{array}$ \\
\hline Isi bait 3 & $\begin{array}{l}\text { Boneh, lumbuang, } \\
\text { numpun, sawah. }\end{array}$ & $\begin{array}{c}\text { Kok lai sampai } \\
\text { babuah boneh } \\
\text { Nan sabatang ka } \\
\text { masuak humbuang } \\
\text { Rumpun di sawah } \\
\text { kana juo }\end{array}$ & $\begin{array}{c}\text { Harapan agar selalu } \\
\text { mengingat arti } \\
\text { penting sebuah } \\
\text { perjuangan }\end{array}$ \\
\hline Isi bait 4 & $\begin{array}{l}\text { Ampo, boneh, } \\
\text { janjang. }\end{array}$ & $\begin{array}{l}\text { Mamintak ampo ka } \\
\text { nan boneh } \\
\text { Asa kami tabowo } \\
\text { pulang } \\
\text { Sahinggo janjang jadi } \\
\text { juo }\end{array}$ & $\begin{array}{c}\text { Harapan untuk } \\
\text { mendapatkan } \\
\text { pengakuan yang sama } \\
\text { meskipun berbeda } \\
\text { secara nilai }\end{array}$ \\
\hline Isi bait 5 & $\begin{array}{l}\text { Padi, salibu, tagalu- } \\
\text { galu. }\end{array}$ & $\begin{array}{c}\text { Padi nan masak ka } \\
\text { basabik } \\
\text { Salibu usah } \\
\text { ditinggakan } \\
\text { Tagalu-galu dapek } \\
\text { juo }\end{array}$ & $\begin{array}{c}\text { Sekecil apapun } \\
\text { sesuatu itu pasti } \\
\text { memiliki nilai guna } \\
\text { dan mamfaat }\end{array}$ \\
\hline
\end{tabular}

\section{KESIMPULAN DAN SARAN}

\section{Kesimpulan}

Latar belakang masyarakat suatu etnis pada umumnya selalu tercermin pada seni budaya yang dimilikinya. Begitu juga dengan etnis Minangkabau, yang secara geografis merupakan wilayah agraris, dan sebagian besar masyarakatnya hidup dari hasil menggarap lahan pertanian. Fenomena tersebut kemudian menjadi inspirasi dalam pelahiran karya-karya sastra, seperti dendang. Kasus yang dapat dilihat pada dendang kampar basiang yang sanat cenderung mengunakan teks yang berkaintan dengan kehidupan sosial masyarakat Minagkabau, salah satunya adalah aktivitas bertani.

Frase kalimat sampiran pada dendang kampar basiang sangat jelas mengambarkan kehidupan masyarakat agraris. Begitu juga pada frase kalimat isi yang juga memakai kalimat yang mencerminkan pola-pola masyarakat agraris yang dikemas dalam bentuk sindiran dan kiasan yang sarat akan nilai pengajaran yang mencerminkan sikap kelokalan masyarakat Minangkabau yang sedang berpetuah, dan saling mengingatkan dengan mengunakan bahasa yang halus lagi sopan.

\section{Saran}

1).Untuk para peneliti besar harapan penulis untuk karya ilmiah yang telah tercipta dengan penuh kesederhanaan ini bisa menjadi ukuran dan perbandingan bagi penulis dalam membuat dalam membuat karya tulis. Selain itu bisa menjadi bahan apresiasi dan referensi bagi peneliti, semoga dapat 


\section{Gorga Jurnal Seni Rupa \\ Volume 07 Nomor 02 \\ p-ISSN: 2301-5942 | e-ISSN: 2580-2380}

meningkatkan apresiasi dan ketajaman terhadap fenomena masyarakat yang ada di Indonesia kususnya. 2).Untuk mahasiswa sebagai tawaran alternatif untuk memacu para mahasiswa, penikmat dan pelaku seni lain yang mengapresiasi, agar selalu berusaha menanamkan semangat kreativitas yang bisa melahirkan karya tulis yang berpijak pada teks dendang.

3).Bagi generasi muda Minangkabau sebaiknya sejak dini belajar akan kesenian tradisi agar menimbulkan kecintaan terhadap budaya sendiri.

\section{DAFTAR RUJUKAN}

Adam, Boestanol Arifin. 1980. Salueng dan Dendang di Luhak Nan Tigo Minangkabau Sumatera Barat. Laporan Penelitian Padangpanjang: ASKI Padangpanjang.

Ahimsa-Putra, Ade,(ed). 2000. Wacana Seni dalam Antropologi, dalam Ketika Orang Jawa Nyeni. Yogyakarta: Galang Press.

Departemen Pendidikan Dan Kebudayaan. 1999. Kamus Besar Bahasa Indonesia. Cetakan X. Jakarta: Balai Pustaka.

Fananie, Zainuddin. 2001. Telaah Sastra. Cetakan II. Surakarta: Universitas Muhammadiyah Surakarta.

Kartika, Dharsono Sony \& Perwira, Nanang Ganda. 2004. Pengantar Estetika. Cetakan I. Bandung: Rekayasa Sains.

Koentjaraningrat. 2000. Pengantar Ilmu Antropologi. Cetakan VIII. Jakarta: Rineka Cipta..

Moussay, Gerard. 1998. Tata Bahasa Minangkabau. Jakarta: Kepustakaan Populer Gramedia.

Nafis, Anas. 2004. Dewi Sang Pelindung, dalam Animisme di Minangkabau. Disadur dari Berita Koto Gadang Th. IX - 1934. Cetakan I. Padang: Pusat Pengkajian Islam dan Minangkabau (PPIM) Sumatera Barat.

Netll, Bruno. 2012. Teori dan Metode Dalam Etnomusikologi. Jayapura: Jayapura Center of Music.

Purwadi \& Purnomo, Eko Priyo. 2005. Kamus Sansekerta Indonesia E-book. Yogyakarta: Budaya Jawa.com.

Ratna, Nyoman Kuta. 2011. Antropologi Sastra: Peranan Unsur-Unsur Kebudayaan dalam Proses Kreatif. Cetakan I. Yogyakarata: Pustaka Pelajar..

Sumardjo, Jakob. 2006. Estetika Paradoks. Cetakan I. Bandung: Sunan Ambu Pers.

Suriadiredja, Purwadi. 2003. Manusia, Kebudayaan, dan Kesenian, dalam Guratan Budaya dalam Perspektif Multikultural. Cetakan I.
Denpasar: Fakultas Sastra dan Budaya Universitas Udayana. 